\title{
The effect of energy source and feeding level on the hormones of the entero-insular axis and plasma glucose in the growing pig
}

\author{
BY A. A. PONTER* AND D. N. SALTER \\ Institute of Grassland and Environmental Research, Church Lane, Shinfield, Berkshire RG2 $9 A Q$ \\ AND L. M. MORGAN AND P. R. FLATT \\ Department of Biochemistry, University of Surrey, Guildford, Surrey GU2 $5 \mathrm{XH}$
}

(Received 3 August 1990 - Accepted 25 February 1991)

\begin{abstract}
The aim of the experiment was to test the theory that accustoming pigs to a high-fat diet causes exaggerated gastric inhibitory polypeptide (GIP) secretion in response to a high-fat meal, and to determine whether hypersecretion of GIP could be related to an increase in the GIP content of the small intestine. Twenty-four pigs were fed one of three dietary regimens for 11 weeks : a high-carbohydrate diet $\left(C_{L}\right)$, or a high-fat diet $\left(F_{L}\right)$, both fed at $1.46 \mathrm{MJ}$ gross energy $(\mathrm{GE}) / \mathrm{kg}$ live weight ${ }^{0.75}$ per $\mathrm{d}$, or a highfat diet $\left(F_{H}\right)$ fed at $2.10 \mathrm{MJ} \mathrm{GE} / \mathrm{kg}$ live weight ${ }^{075}$ per $\mathrm{d}$. At the end of the period two acute tests were performed. For acute test 1 the accustomed meal (diets $C_{L}, F_{L}$ and $F_{H}$ ) and for acute test 2 a standard high-fat meal (diet $F_{L}$ ) were given; blood samples were taken during the next $5 \mathrm{~h}$ and analysed for GIP, insulin and glucose. Integrated increases in hormone and glucose levels were compared by analysis of variance $(0-300 \mathrm{~min})$. In acute test 1 there were significantly different plasma GIP concentrations between groups $\left(C_{L}>F_{H}>F_{L} ; P<0.05\right)$. Plasma insulin concentrations were significantly higher in group $C_{L}$ compared with groups $F_{L}$ and $F_{H}(P<0.002)$. There were no differences in glucose levels. In acute test 2 integrated increases in plasma GIP $(0-300 \mathrm{~min})$ concentrations were not significantly different ; however, GIP (0-45 min) concentrations were significantly higher in group $F_{H}$ than in groups $C_{L}$ and $F_{L}(P<0.05)$. There were no differences in plasma insulin concentrations. Plasma glucose (0-300 min) concentrations were significantly higher in groups $F_{L}$ and $F_{H}$ compared with group $C_{L}$ $(P<0.05)$. The GIP content of tissue samples taken at the end of the experiment from the duodenum, jejunum, upper and lower ileum decreased significantly in a proximal to distal direction $(P<0.001)$. Diet $F_{H}$ significantly increased the average GIP content of the small intestine compared with diets $C_{L}$ and $F_{L}$ $(P<0.05)$. It is concluded that fat meal-stimulated GIP secretion was enhanced by increased feeding level during a pre-treatment phase, possibly due to an increase in GIP synthesis in the small intestine. The high-fat diet caused glucose intolerance after a high-fat meal. This may be due in part to the action of dietary fat on glucose transport and metabolism.
\end{abstract}

Entero-insular axis: High-fat diets: Pigs

The gastrointestinal hormone gastric inhibitory polypeptide (GIP), secreted by the K-cells of the small intestine (Polak et al. 1973), has been shown to stimulate insulin release when blood glucose levels are raised (Brown et al. 1975). The integrated system of gut stimuli (neural, endocrine and substrate factors) which controls the release of insulin is known as the entero-insular axis (EIA ; Creutzfeldt, 1979). One of the main candidates for endocrine stimulation is GIP.

GIP is secreted in response to the absorption of fat (Brown et al. 1975), carbohydrate (Sykes et al. 1980) and amino acids (Thomas et al. 1978). The secretion of GIP can be manipulated through the diet; for example, a high-fat diet increases fat-stimulated GIP in

* Present address: I.N.R.A., Station de Recherches Porcines, St Gilles, 35590 L'Hermitage, France. 
Table 1. Diet composition and analysis

\begin{tabular}{|c|c|c|}
\hline & High-carbohydrate & High-fat \\
\hline \multicolumn{3}{|l|}{ Composition $(\mathrm{g} / \mathrm{kg})$} \\
\hline Maize starch & 581 & 179 \\
\hline Sucrose & 100 & 85 \\
\hline Soya-bean oil & 15 & 170 \\
\hline Flaked tallow & 15 & 170 \\
\hline Casein & 180 & 248 \\
\hline Solka floc & 60 & 82 \\
\hline Vitamins and minerals & 50 & 68 \\
\hline \multicolumn{3}{|l|}{ Analysis (\%) } \\
\hline Ash & $3 \cdot 91$ & $5 \cdot 74$ \\
\hline Protein & $15.86(14.94)^{*}$ & $23 \cdot 27(20 \cdot 51)$ \\
\hline Fat & $2 \cdot 13(3.25)$ & $29 \cdot 27(34.29)$ \\
\hline Gross energy (MJ/kg) & $17.55(16.50)$ & $23.66(22 \cdot 70)$ \\
\hline Protein: energy (g/MJ) & $9.04(9.05)$ & $9 \cdot 84(9 \cdot 04)$ \\
\hline
\end{tabular}

* Values in parentheses indicate calculated values.

rats (Hampton et al. 1983) and glucose-stimulated GIP in humans (Morgan et al. 1988 b). Also, a low-fat diet reduces the GIP response to a fat meal (Morgan et al. 1988 c). It has been postulated that there is a negative feedback between insulin and fat-stimulated GIP secretion. A high-fat diet abolishes the inhibition of exogenous insulin on fat-stimulated GIP secretion in both rats (Hampton et al. 1983) and man (Morgan et al. 1983). Intravenous glucose attenuates the response of GIP to oral fat; however, this has been related to the rate of gastric emptying (Morgan et al. 1988c).

Western diets contain high levels of fat compared with the diets eaten in developing countries. It has been noted that the incidence of obesity and type II diabetes are also high in Western countries. It has been suggested, therefore, that the development of these disease states could be due, in part, to the influence of the diet and on an overactive entero-insular axis. It has been postulated that the EIA is overactive because the negative feedback of insulin on fat-stimulated GIP secretion is impaired. Exaggerated GIP concentrations have been seen in obese subjects after a mixed meal (Ebert et al. 1976; Jones et al. 1989), however, this has not been substantiated by other workers (Service et al. 1984). GIP is also directly involved in fat deposition (Eckel et al. 1979; Beck \& Max, 1986a).

The experiment reported here was designed to investigate whether hormones and metabolites of the EIA in pigs respond to a high-fat diet in the same way as in humans and rats. It was also to determine whether any change in GIP levels could be related to a change in the GIP content of the small intestine. A preliminary report of part of the present work has been presented previously (Ponter et al. 1990).

\section{MATERIALS AND METHODS}

\section{Animals and diets}

Two semi-purified diets were formulated, one high in carbohydrate and the other high in fat (Table 1). Three dietary regimens were formulated from the two diets: highcarbohydrate diet $\left(\mathrm{C}_{\mathrm{L}}\right)$, high-fat diet $\left(\mathrm{F}_{\mathrm{L}}\right)$, both fed at $1.46 \mathrm{MJ}$ gross energy $(\mathrm{GE}) /$ $\mathrm{kg}$ live weight ${ }^{0 \cdot 75}$ per $\mathrm{d}$, and high-fat diet $\left(\mathrm{F}_{\mathrm{H}}\right)$ fed at $2 \cdot 10 \mathrm{MJ} \mathrm{GE} / \mathrm{kg}$ live weight ${ }^{0.75}$ per $\mathrm{d}$. The three dietary regimens were given for 11 weeks to twenty-four Large White $\times$ Landrace pigs (eight litters of three pigs) twice daily at 09.00 and 16.00 hours. The 
feed was mixed in the proportion $1: 2 \cdot 5$ with water. Water was also supplied $a d$ lib. throughout the experimental period. After 8 weeks of feeding the dietary regimens a surgical operation was performed on each pig to insert a jugular catheter. After the operations each animal received a $1 \mathrm{ml}$ subcutaneous injection of 'Penbritin' (Beecham Animal Health, Middlesex) on three successive days. The catheter was exteriorized onto the back of the animal and held secure by an elastic bandage. The patency of the catheter was maintained by flushing with heparinized saline $(9 \mathrm{~g}$ sodium chloride/l containing $10 \mathrm{IU}$ heparin (heparin sodium, Evans Medical Ltd, Middlesex)/ml). The pigs were housed in individual pens at a temperature of $20^{\circ}$ and then moved into metabolism crates 1 week before blood sampling.

At $5 \mathrm{~d}$ after acute test 2 the pigs were slaughtered by captive bolt and exsanguinated. The digestive tract was quickly excised and washed in ice-cold saline to remove undigested feed and faeces. The small intestine was divided into four equal-length sections, approximately corresponding to the duodenum, jejunum, upper ileum and lower ileum, and a $500 \mathrm{~mm}$ piece was taken from the centre of each section and frozen.

\section{Acute tests}

Two acute tests were performed to determine the effect of feeding; (1) the accustomed meal that the animals had been receiving for the previous 9 weeks and (2) the high-fat meal (diet $F_{L}$ ) irrespective of the regimen to which they had been accustomed. Acute test 1 was done $7 \mathrm{~d}$ after insertion of the catheter and test 2 after $16 \mathrm{~d}$. The meals comprised a normal 09.00 hours allocation of feed (half the daily amount). On the pre-experiment days the pigs were given the accustomed meal at 16.00 hours; this was rapidly consumed ( $<45 \mathrm{~min}$ ). The animals were then fasted until 09.00 hours the next day when they were given the acute-test meals. Blood samples were taken from conscious pigs during the two acute tests, as follows:

Acute test 1 (accustomed meal). Blood samples were taken $10 \mathrm{~min}$ before the test feed and at $0,10,20,30,45,60,90,120,180,240$ and $300 \mathrm{~min}$ following presentation of the test feed (i.e. one of the three dietary regimens). The blood samples were immediately centrifuged at $1500 \mathrm{rev} . / \mathrm{min}$ for $20 \mathrm{~min}$ at $4^{\circ}$ after collection in lithium heparinized tubes (Sterilin Ltd, Feltham) and stored at $-20^{\circ}$ until analysed.

Acute test 2. Blood samples were taken and stored as described previously, in relation to a standard high-fat meal (i.e. the morning allowance of the high-fat diet $F_{L}$ ).

\section{Analyses}

Plasma glucose concentrations were measured using a glucose oxidase $(E C 1.1 .3 .4) \mathrm{kit}$ (Baker Instruments, USA) on a fully-automated clinical analyser (Encore Clinical Chemistry System, Baker Instruments, USA). Systemic plasma immunoreactive insulin and GIP were measured using the double-antibody technique (Guildhay Antisera, Guildford; Morgan et al. 1978). GIP is mainly cleared from the plasma by the kidney (O'Dorisio et al. 1977), therefore systemic concentrations of GIP represent the 'active' concentrations encountered by tissues. It was not possible to make a more accurate estimate of insulin secretion from venous blood samples through the measurement of $\mathrm{C}$-peptide due to the lack of an assay for porcine C-peptide. The sensitivity limit of the insulin assay was $3 \mathrm{mU} / 1$ and for the GIP assay $125 \mathrm{pg} / \mathrm{ml}$. The sensitivity limit was defined as the lowest concentration of hormone distinguishable from zero. The standard deviation of a large number of 'zero' tubes was determined. The sensitivity limit was then calculated as a point on the standard curve which corresponded to a decrease of two standard deviations from 'zero' binding. The inter-assay coefficients of variation for insulin and GIP were $17 \cdot 1$ and $8.2 \%$ respectively. The intra-assay coefficients of variation were $12 \cdot 2$ and $6.5 \%$ for insulin and GIP respectively. 
Table 2. The effect of dietary regimen on the mean integrated* responses of plasma gastric inhibitory polypeptide (GIP), insulin and glucose to acute test 1 (the accustomed meal)

\begin{tabular}{|c|c|c|c|c|c|}
\hline Dietary group $† \ldots$ & $\mathrm{C}_{\mathrm{L}}$ & $\mathbf{F}_{\mathrm{L}}$ & $\mathrm{F}_{\mathrm{H}}$ & SED & $\begin{array}{c}\text { Residual } \\
\mathrm{df}\end{array}$ \\
\hline \multicolumn{6}{|l|}{ Acute test $1 \ddagger$} \\
\hline GIP (ng / 1 per $\min )(0-300 \mathrm{~min})$ & $3330^{\mathrm{a}}$ & $1670^{\circ}$ & $2330^{\mathrm{b}}$ & $243 \cdot 0$ & 8 \\
\hline Insulin $(\mathrm{mU} / 1$ per $\mathrm{min})(0-300 \mathrm{~min})$ & $65 \cdot 0^{\mathrm{a}}$ & $31 \cdot 0^{\mathrm{b}}$ & $30 \cdot 3^{b}$ & $7 \cdot 33$ & 8 \\
\hline Glucose $(\mathrm{mmol} / 1$ per $\mathrm{min})(0-300 \mathrm{~min})$ & $5 \cdot 20$ & $5 \cdot 90$ & $5 \cdot 40$ & $0 \cdot 333$ & 9 \\
\hline
\end{tabular}

a.b,c Mean values within rows with different superscript letters were significantly different $(P<0 \cdot 05)$.

$\mathrm{C}_{\mathrm{L}}$, high-carbohydrate diet; $\mathrm{F}_{\mathrm{L}}, \mathrm{F}_{\mathrm{H}}$, high-fat diet fed at 1.46 and $2.10 \mathrm{MJ}$ gross energy $/ \mathrm{kg}$ live weight ${ }^{0.75}$ per $\mathrm{d}$ respectively; SED, standard error of difference.

* The integrated $(0-300 \mathrm{~min})$ values were calculated by integration using a maximum likelihood programme (Ross, 1980).

$\uparrow$ For details of diets and dietary regimens, see Table $\mathrm{I}$ and p. 188 .

+ For details, see p. 189 .

The small intestine sections were analysed for GIP. Approximately $4 \mathrm{~g}$ tissue were taken from the centre of each $500 \mathrm{~mm}$ piece and extracted with acid ethanol $(750 \mathrm{ml}$ ethanol, $250 \mathrm{ml}$ water, $15 \mathrm{ml}$ concentrated hydrochloric acid), $5 \mathrm{ml} / \mathrm{g}$ tissue. The GIP contents of tissues were analysed using the GIP assay previously described, using samples appropriately diluted with distilled water to bring them onto the standard curve (Flatt et al. 1983).

The diets were analysed for ash, protein, gross energy and fat. Ash was determined by ignition at $550^{\circ}$ for two days in a muffle furnace (Gallenkamp). Nitrogen was determined by Kjeldahl digestion followed by colorimetric assay of the digest using a continuous, segmented-flow colorimetric analyser (ChemLab); crude protein was given as $\mathrm{N} \times 6.25$. Gross energy was measured by ignition in an adiabatic bomb calorimeter (Gallenkamp). The fat content was determined by Soxhlet extraction with light petroleum $40-60^{\circ}$.

\section{Statistical analysis}

The effects of treatment on plasma concentrations of insulin, GIP and glucose were compared using a randomized-block design analysis of variance (litters were treated as blocks) of the uncorrected area under the time curves. The area under the curve was calculated by integration using a maximum likelihood programme (MLP; Ross, 1980). The analysis of variance was performed using a GENSTAT V (Lawes Agricultural Trust, 1990) programme. The intestinal GIP results were also compared by analysis of variance (GENSTAT V) where the litters were treated as blocks.

\section{RESULTS}

\section{Concentrations of hormones and metabolites in blood}

The time curves of plasma GIP, insulin and glucose concentrations for acute test 1 are shown in Fig. 1 ( $a, b$ and $c$ respectively). Those for acute test 2 are shown in Fig. 2 ( $a, b$ and $c$ respectively). Tables 2 and 3 show integrated increases in plasma concentrations of GIP, insulin and glucose for acute tests 1 and 2 respectively. Fasting levels of GIP, insulin and glucose were unaffected by dietary treatment.

Acute test 1. Plasma GIP concentrations in the high-carbohydrate regimen group $\mathrm{C}_{\mathrm{L}}$ pigs peaked earlier and were significantly higher than in high-fat groups $F_{L}$ and $F_{H}$. Group $F_{H}$ pigs had significantly higher integrated plasma GIP concentrations than group $F_{\mathrm{I}}$ in the 

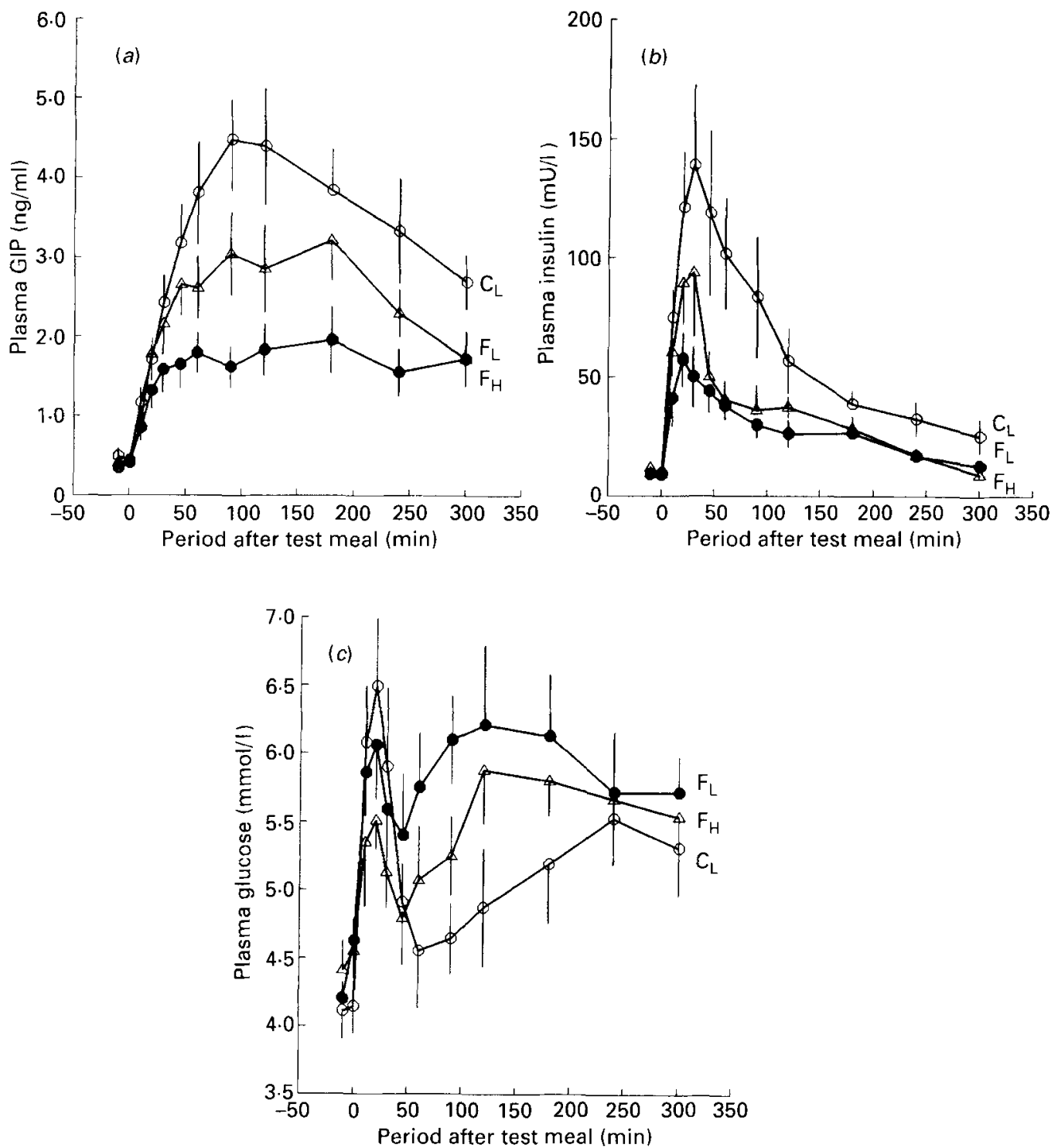

Fig. 1. Plasma gastric inhibitory polypeptide (GIP; $a$ ), insulin $(b)$, and glucose $(c)$ concentrations after acute test 1 (the accustomed meal) for the three dietary groups: $(O)$, high-carbohydrate diet $\left(\mathrm{C}_{\mathrm{L}}\right)$ and $(\odot, \triangle)$ high-fat diet fed at $1.46\left(F_{L}\right)$ and $2 \cdot 10\left(F_{11}\right)$ MJ gross energy $/ \mathrm{kg}$ live weight ${ }^{0.75}$ per d respectively (for details, see Table 1 and p. 188). Points are means with their standard errors represented by vertical bars for eight pigs. For details of procedures, see p. 189.

periods $0-240$ and $0-300 \mathrm{~min}$. The shapes of the curves for groups $\mathrm{F}_{\mathrm{L}}$ and $\mathrm{F}_{\mathrm{H}}$ were similar. (Fig. 1(a)).

Over the whole sampling period group $C_{L}$ pigs had higher integrated plasma insulin levels than groups $F_{L}$ or $F_{H}$ pigs. Insulin concentrations were not significantly different between groups $\mathrm{F}_{\mathrm{I}}$, and $\mathrm{F}_{\mathrm{H}}$ and the curves were very similar in shape. (Fig. $1(b)$ ).

At the end of the sampling period there were no differences in integrated glucose levels between groups. However, there was a trend for group $F_{L}$ pigs to have higher levels of 
Table 3. The effect of dietary regimen on the mean integrated* responses of plasma gastric inhibitory polypeptide $(G I P)$, insulin and glucose to acute test 2 (the standard high-fat diet)

\begin{tabular}{|c|c|c|c|c|c|}
\hline Dietary group $\dagger \ldots$ & $\mathrm{C}_{\mathrm{L}}$ & $\mathrm{F}_{\mathbf{L}}$ & $\mathrm{F}_{\mathrm{H}}$ & SED & $\begin{array}{c}\text { Residual } \\
\mathrm{df}\end{array}$ \\
\hline \multicolumn{6}{|l|}{ Acute test $2+$} \\
\hline GIP $(\mathrm{ng} / 1$ per $\min )(0-300 \mathrm{~min})$ & 1540 & 1790 & 2154 & $238 \cdot 0$ & 6 \\
\hline GIP (ng/l per min) $(0-45 \mathrm{~min})$ & $1184^{\mathrm{b}}$ & $1300^{b}$ & $1816^{\mathrm{a}}$ & $177 \cdot 9$ & 6 \\
\hline Insulin $(\mathrm{mU} / 1$ per $\mathrm{min})(0-300 \mathrm{~min})$ & $32 \cdot 7$ & $27 \cdot 3$ & $34 \cdot 3$ & $5 \cdot 33$ & 7 \\
\hline Glucose $(\mathrm{mmol} / 1$ per $\mathrm{min})(0-300 \mathrm{~min})$ & $3.87^{\mathrm{b}}$ & $4 \cdot 63^{\mathrm{a}}$ & $4 \cdot 17^{\mathrm{a}}$ & $0 \cdot 133$ & 6 \\
\hline
\end{tabular}

${ }^{a, h}$ Mean values within rows with different superscript letters were significantly different $(P<0.05)$.

$\mathrm{C}_{\mathrm{L}}$, high-carbohydrate diet; $\mathrm{F}_{\mathrm{L}}, \mathrm{F}_{\mathrm{H}}$, high-fat diet fed at $\mathrm{I} \cdot 46$ and $2 \cdot 10 \mathrm{MJ}$ gross energy $/ \mathrm{kg}$ live weight ${ }^{075}$ per $\mathrm{d}$ respectively; SED, standard error of difference.

* The integrated $(0-300 \mathrm{~min})$ values were calculated by integration using a maximum likelihood programme (Ross, 1980).

$\dagger$ For details of diets and dietary regimens, see Table 1 and p. 188

¥ For details, see p. 189.

integrated glucose $(0-300 \mathrm{~min})$ than group $\mathrm{C}_{\mathrm{L}}$ pigs $(P=0.087)$. The shapes of the curves for groups $F_{L}$ and $F_{H}$ were again similar. After the initial peak (at $20 \mathrm{~min}$ ) and trough in blood glucose levels, there was a gradual increase in the concentrations which were maintained for the rest of the sampling period (Fig. 1(c)).

Acute test 2 . The integrated GIP levels after $300 \mathrm{~min}$ were not significantly different between groups, although there was a tendency $(P=0 \cdot 10)$ for group $\mathrm{F}_{\mathrm{H}}$ pigs to have higher GIP levels than $C_{L}$ (Table 3 ). The curves for groups $F_{L}$ and $F_{H}$ were again very similar. The integrated areas from $0 \mathrm{~min}$ up to $20,30,45$, and $60 \mathrm{~min}$ were significantly higher in group $F_{\mathrm{H}}$ pigs than group $\mathrm{C}_{\mathrm{L}}$ pigs $(P<0.05)$. The plasma GIP concentrations increased in group $F_{H}$ while those in group $C_{\mathrm{T}}$ decreased during the time-period $30-60 \mathrm{~min}$, therefore the difference was maintained. The integrated area from $0 \mathrm{~min}$ up to $30 \mathrm{~min}$ was significantly higher in group $\mathrm{F}_{\mathrm{H}}$ compared with $\mathrm{F}_{\mathrm{L}}(P<0.05)$, and this difference was maintained for the time-period $0-45 \mathrm{~min}$ due to the continued divergence of the response curves (Fig. $2(a)$ ).

Plasma insulin levels in group $C_{L}$ pigs peaked and fell very quickly compared with groups $F_{L}$ and $F_{H}$ which peaked at much lower levels but remained higher for longer. The integrated levels of insulin were significantly higher in group $C_{L}$ compared with group $F_{L}$ in the time-periods $0-10,0-20$, and $0-30 \mathrm{~min}$ but thereafter there were no differences between groups. Over the whole sampling period there were no differences in integrated plasma insulin (Fig. 2(b)).

Plasma glucose concentrations reached similar peak concentrations for all groups, but thereafter group $F_{L}$ had significantly higher levels than groups $C_{L}$ and $F_{H}$ at all time-points. Group $F_{H}$ pigs had higher integrated glucose concentrations than group $C_{L}$ pigs from 0 min up to $45,60,90,120$ and $180 \mathrm{~min}$. A similar blood glucose profile was seen in this acute test compared with acute test 1 ; after the initial fluctuations in glucose concentrations they gradually increased to levels which were higher than basal and remained at these levels for the remainder of the sampling period (Fig. 2(c)).

\section{Intestinal GIP analysis}

The GIP concentration of small intestinal tissue (Table 4) decreased significantly in a proximal to distal direction, i.e. the highest concentrations of GIP were found in the duodenum $>$ jejunum $>$ upper ileum $>$ lower ileum sections $(P<0.001)$. Analysis of variance showed that dietary regimen $F_{H}$ significantly increased the GIP content of the 

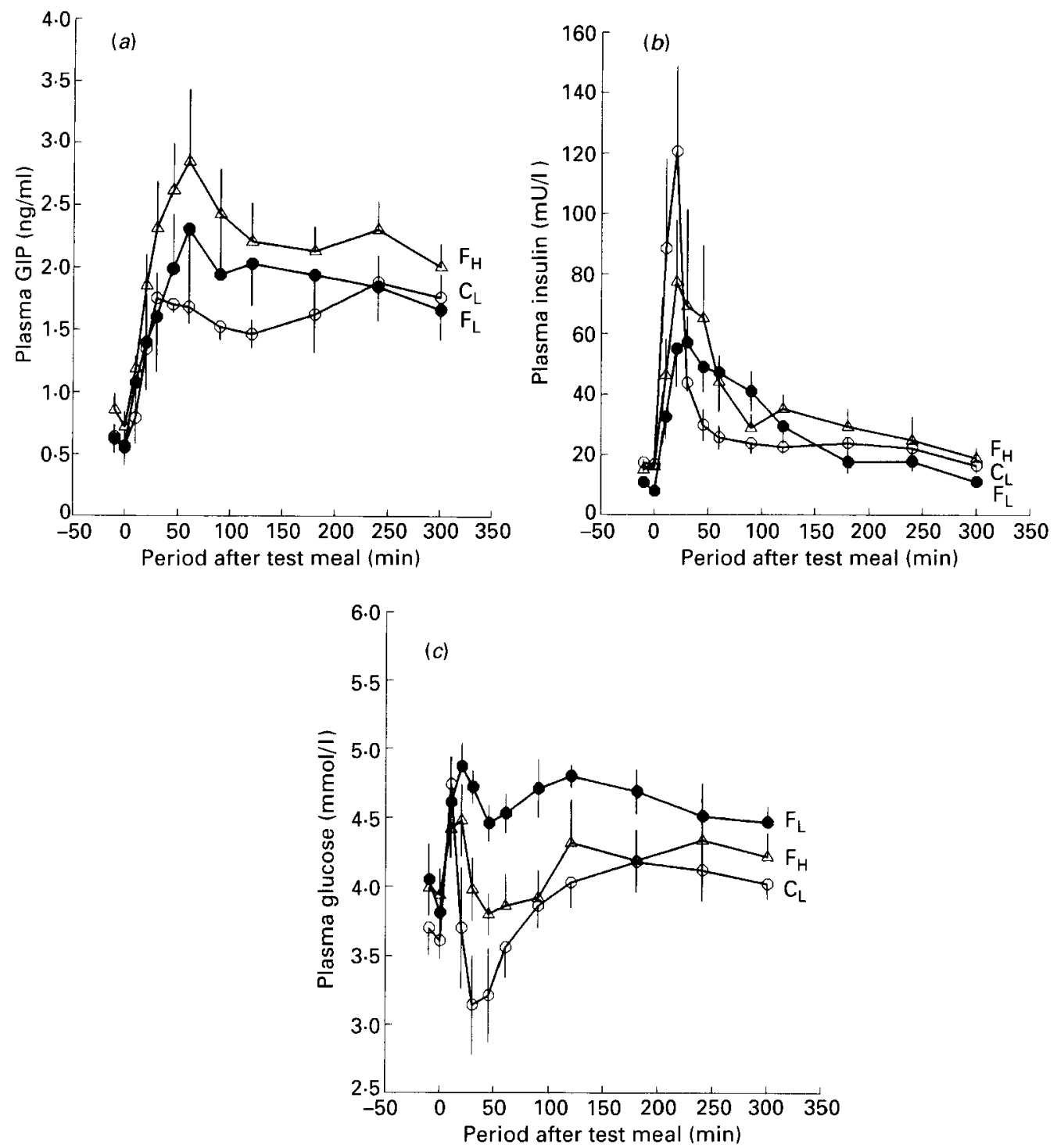

Fig. 2. Plasma gastric inhibitory polypeptide (GIP; $a$ ), insulin $(b)$, and glucose $(c)$ concentrations after acute test 2 (the standard high-fat meal) for the three dietary groups: $(O)$, high-carbohydrate diet $\left(C_{\mathrm{L}}\right)$ and $(\bigcirc, \triangle)$ highfat diet fed at $1.46\left(\mathrm{~F}_{\mathrm{L}}\right)$ and $2 \cdot 10\left(\mathrm{~F}_{11}\right) \mathrm{MJ}$ gross energy/kg live weight ${ }^{\mathbf{7} 75}$ per $\mathrm{d}$ respectively (for details, see Table 1 and p. 188). Points are means with their standard errors represented by vertical bars for eight pigs. For details of procedures, see p. 189.

duodenum and upper ileum $(P<0.05)$ and tended to increase that of the jejunum and lower ileum when compared with diets $\mathrm{C}_{\mathrm{L}}$ and $\mathrm{F}_{\mathrm{L}}$. The mean GIP content of the four segments was greater with dietary regimen $\mathrm{F}_{\mathrm{H}}$ compared with diets $\mathrm{C}_{\mathrm{L}}$ and $\mathrm{F}_{\mathrm{L}}(P<0.05)$.

\section{DISCUSSION}

The present experiment showed that when a predominantly fat or carbohydrate meal was fed at the same energy level (acute test 1 ), the carbohydrate meal produced significantly 
Table 4. The gastric inhibitory polypeptide $(G I P)$ concentration in sections of the small intestine (ng/g tissue)

(Values are means for eight pigs)

\begin{tabular}{lccccc}
\hline \hline $\begin{array}{l}\text { Dietary group* } \ldots \\
\text { Section }\end{array}$ & $\mathrm{C}_{\mathrm{L}}$ & $\mathrm{F}_{\mathrm{L}}$ & $\mathrm{F}_{\mathrm{I1}}$ & SED & Residual df \\
& & & & & \\
\hline Duodenum & $1917^{\mathrm{b}}$ & $1930^{\mathrm{b}}$ & $2391^{\mathrm{a}}$ & $168 \cdot 9$ & 10 \\
Jejunum & 1530 & 1543 & 1813 & $169 \cdot 9$ & 11 \\
Upper ileum & $613^{\mathrm{b}}$ & $737^{\mathrm{b}}$ & $882^{\mathrm{a}}$ & $61 \cdot 3$ & 11 \\
Lower ileum & $237^{\mathrm{b}}$ & 190 & 302 & $65 \cdot 5$ & 11 \\
Mean & $1051^{\mathrm{b}}$ & $1104^{\mathrm{b}}$ & $1349^{\mathrm{a}}$ & $79 \cdot 8$ & 11 \\
\hline
\end{tabular}

a.b Mean values within rows with different superscript letters were significantly different $(P<0 \cdot 05)$.

$C_{\mathrm{I}}$, high-carbohydrate diet; $\mathrm{F}_{\mathrm{L}}, \mathrm{F}_{\mathrm{H}}$, high-fat diet fed at 1.46 and $2 \cdot 10 \mathrm{MJ}$ gross energy $/ \mathrm{kg}$ live weight ${ }^{0 \cdot 73}$ per $\mathrm{d}$ respectively; SED, standard error of difference.

* For details of diets and dietary regimens, see Table 1 and p. 188.

higher systemic plasma GIP concentrations than the fat meal. Even feeding the fat meal at a higher energy level did not cause an increase in the GIP levels above the carbohydrate meal. This was unexpected since Penman et al. (1981) showed that when isoenergetic oral loads of glucose or fat were given there were significantly higher plasma GIP concentrations after the fat compared with glucose. When an oral load of glucose or fat was given on a weight basis the fat load produced a higher plasma GIP concentration than the glucose (Williams et al. 1981). These two experiments differed from the present study because a monocomponent load of either fat or glucose was used, whereas in the present study meals which were either predominantly fat or carbohydrate were used. Three possible explanations might account for the differences seen between the experiments: (1) there could be an interaction between the nutrient components of the meal to increase carbohydrate stimulation of GIP concentrations, relative to fat stimulation; (2) gastric emptying may be altered due to meal volume, energy content and fat content; (3) insulin has been shown to inhibit fat-stimulated GIP secretion (Brown et al. 1975). When a pure fat load was given (Penman et al. 1981) insulin release was not stimulated and consequently this negative feedback of insulin on GIP secretion could not have been operating. In the present study when a predominantly fat meal was used some insulin was released in response to the carbohydrate component of the meal which could act in a negative feedback manner on fat-stimulated GIP secretion. The pigs fed on the predominantly carbohydrate meal may, therefore, have had higher plasma GIP levels because there was less fatstimulated GIP to be inhibited by the insulin, compared with the pigs fed on the predominantly fat meals.

The carbohydrate meal produced higher levels of insulin than the two fat meals, presumably because fatty acids are poor stimulators of insulin release compared with carbohydrate (Gerich et al. 1976). Diet $\mathrm{F}_{\mathrm{H}}$ appeared to cause higher initial levels of insulin than diet $\mathrm{F}_{\mathrm{L}}$ (but this did not achieve significance). Although both diets $\mathrm{F}_{\mathrm{I}}$ and $\mathrm{F}_{\mathrm{H}}$ were predominantly fat, diet $F_{H}$ was fed at a higher rate than diet $F_{L}$. Therefore, pigs given diet $\mathrm{F}_{\mathrm{H}}$ received not only more fat but also more carbohydrate than group $\mathrm{F}_{\mathrm{I}}$ pigs, explaining the trend to greater release of insulin.

Post-prandial blood glucose levels after the accustomed meal (acute test 1) were not significantly different except for one time point $(120 \mathrm{~min})$ where group $\mathrm{F}_{\mathrm{I}}$ pigs had higher glucose concentrations than group $\mathrm{C}_{\mathrm{L}}$ or $\mathrm{F}_{\mathrm{H}}$ pigs $(P<0.05)$. Therefore, post-prandial glucose tolerance in acute test 1 was relatively unaffected when the accustomed meal was given in spite of the wide variation in the amount of carbohydrate consumed. 
In acute test 2 the effect of long-term adaptation to the different dietary regimens $\mathrm{C}_{\mathrm{L}}, \mathrm{F}_{\mathrm{L}}$ and $F_{\mathrm{H}}$ on the response when the same high-fat diet was given to all pigs was investigated. In agreement with other workers (Morgan et al. 1988c; Hampton et al. 1983), feeding a high-fat diet caused a greater release of GIP in response to a high-fat meal compared with a high-carbohydrate diet. This effect became significant when the high-fat diet was fed at the highest energy level. A possible explanation for this effect is that the pigs which had the highest plasma GIP concentrations also had the highest GIP concentrations in the small intestine (Table 4). Therefore, for a standard meal there would be more releasable GIP, which would lead to higher GIP concentrations in the plasma. An alternative explanation is that by feeding diets high in fat the mechanisms involved in the digestion and absorption of fat could be stimulated. GIP release is dependent on the absorption of nutrients, therefore if fat digestion and absorption are improved then more GIP could be released. The increased concentrations of GIP seen in the plasma of rats accustomed to a high-fat diet (Hampton et al. 1983) and reduced GIP concentrations seen in humans accustomed to a low-fat diet (Morgan et al. 1988c) after a high-fat meal could be due to the adaptation of the systems involved in fat digestion and absorption. In the present study, however, there were no significant differences in plasma GIP concentrations between the groups $\mathrm{C}_{\mathrm{L}}$ and $\mathrm{F}_{\mathrm{L}}$ after a high-fat meal, which makes this alternative explanation less likely.

The peak insulin response of group $\mathrm{C}_{\mathrm{L}}$ to the standard high-fat meal (acute test 2) was significantly greater than that of group $\mathrm{F}_{\mathrm{L}}$. This is in contrast to studies by Hampton et al. (1983) and Tan et al. (1987) who have shown exaggerated plasma insulin concentrations after feeding rats high-fat diets in response to a glucose load. Morgan et al. (1988b) were, however, unable to confirm this finding with human subjects. The pigs in the present experiment, therefore, appear to resemble humans more closely in this respect, although the nutrient loads used were different. The plasma glucose response to acute test 2 indicates that there may have been a shift in the mechanisms which control blood glucose levels. The post-prandial plasma glucose concentrations in acute test 2 were significantly higher in the pigs accustomed to the high-fat dietary regimens despite the total integrated insulin levels being similar in all groups. There may be two possible reasons for this finding. The first is that glucose disposal potentiated by insulin is impaired. High-carbohydrate diets caused a reduction in insulin-binding ability of adipocytes but enhanced glucose transport and metabolism (Olefsky \& Saekow, 1978), while high-fat diets resulted in a reduction in the number of insulin receptors and their affinity on hepatocyte plasma membranes and adipocytes (Sun et al. 1977). The second is that the rate of hepatic glycogenolysis could be altered.

The time taken to reach peak post-prandial concentrations of GIP varied according to the dietary treatments (Figs $1(a)$ and $2(a)$ ). This was probably due to a combination of effects; gastric emptying rate (meal volume, energy and fat content) and secretagogue potential of the different components of the meals. Ebert \& Creutzfeldt (1982) have shown that GIP is an important insulinotropic agent for the first 20 min after a glucose load in rodents, when plasma glucose concentrations are raised; thereafter other factors become involved. The high GIP levels observed in the later part of the sampling period may, therefore, have more important effects on fat metabolism than insulin secretion. It would be expected that pigs accustomed to a high-carbohydrate diet would become adapted to dispose of the high levels of glucose being absorbed. In order to do this the activity of GIP on the $\beta$-cell to release insulin may be enhanced by an increase in receptor numbers and their affinity for GIP. With respect to this, Beck \& Max (1986b) have shown that the glucose threshold needed before GIP acted to release insulin was lower in obese compared with lean Zucker fatty rats. They suggested that this change was due to an alteration in the receptor for GIP. This may help explain what appears to be an inappropriately high insulin 
response in group $\mathrm{C}_{\mathrm{L}}$ pigs after acute test 2 (Fig. 2(b)) compared with the other groups when plasma GIP concentrations were not different at this time point (Fig. 2(a)).

The estimation of GIP within the digestive tract sections gave a comparative measure of the GIP concentration at four equally-spaced points within the small intestine. To facilitate identification these points were labelled as coming from the duodenum, jejunum, upper and lower ileum; however, this was not a true anatomical description of where the measurements were made. The estimation of GIP within the small intestine showed that the concentration decreased progressively in a proximal to distal direction. This is in agreement with work by Bunnett \& Harrison (1986) in sheep, Bloom \& Polak (1978) in humans and O'Dorisio et al. (1976) in dogs. The concentrations of GIP within the small intestine are influenced by the level of feeding and not the type of diet. The difference in total GIP contents of the gut may explain in part the difference seen in the response to a high-fat meal exhibited by the treatment groups. These findings are consistent with the theory proposed by Morgan et al. (1988 a), who suggest that hyperphagia causes hypersecretion of GIP. In addition the level of fat in the spontaneous or 'normal' diet may influence the degree to which the GIP response to different nutrients can be manipulated. Rats normally eat a diet low in fat ( $3 \%$ of dietary energy as fat) as do pigs ( $5 \%$ of dietary energy as fat), but humans eating a Western diet eat much higher levels of fat $(42.6 \%$ of the dietary energy as fat; Committee on Medical Aspects of Food Policy, 1984). This emphasizes the care which needs to be taken when comparing the results from dietary manipulation experiments which have used different species.

A.A.P. would like to acknowledge the financial support of the AFRC Institute for Grassland and Environmental Research during the experiment. The authors would like to thank Dr D. Lister and Mrs C. Jones for performing the surgery, Dr A. Rook for statistical advice and J. A. Taylor and Mrs E. J. Stockton for care of the animals.

\section{REFERENCES}

Beck, B. \& Max, J.-P. (1986a). Direct metabolic effects of gastric inhibitory polypeptide (GIP): dissociation at physiological levels of effects on insulin-stimulated fatty acid and glucose incorporation in rat adipose tissue. Diabetologia 29, 68.

Beck, B. \& Max, J.-P. (1986 b). Increased effect of GIP on lipid metabolism in adipose tissue of obese Zucker (fa/fa) rats. In Proceedings of the 6th International Conference on Gastrointestinal Hormones, p. 53. Vancouver, $\mathrm{BC}$ and Ottawa: National Research Council of Canadian Research Journals.

Bloom, S. R. \& Polak, J. M. (1978). Gut hormones overview. In Gut Hormones, pp. 3.18 [S. R. Bloom, editor]. Edinburgh, London and New York: Churchill Livingstone.

Brown, J. C., Dryburgh, J. R., Ross, S. E. \& Dupré, J. (1975). Identification and actions of gastric inhibitory polypeptide. Recent Progress in Hormone Research 32, 487-532.

Bunnett, N. W. \& Harrison, F. A. (1986). Immunological localisation of gastric inhibitory polypeptide and glucagon in the alimentary tract of ruminants. Quarterly Journal of Experimental Physiology 71, 433-441.

Creutzfeldt, W. (1979). The incretin concept today. Diabetologia 16, 75-85.

Department of Health and Social Security (1984). Diet and Cardiovascular Disease. Committee on Medical Aspects of Food Policy. Report of the Panel on Diet in relation to Cardiovascular Disease. Report on health and social subjects no. 28. London: H.M. Stationery Office.

Ebert, R. \& Creutzfeldt, W. (1982). Influence of gastric inhibitory polypeptide antiserum on glucose-induced insulin secretion in rats. Endocrinology 111, 1601-1606.

Ebert, R., Willms, B., Brown, J. C. \& Creutzfeldt, C. (1976). Serum gastric inhibitory polypeptide (GIP) levels in obese subjects and after weight reduction. European Journal of Clinical Investigation 6, 327A.

Eckel, R. H., Fujimoto, W. Y. \& Brunzell, J. D. (1979). Gastric inhibitory polypeptide enhanced lipoprotein lipase activity in cultured preadipocytes. Diabetes $\mathbf{8}, 1141-1142$.

Flatt, P. R., Bailey, C. J., Kwasowski, P., Swanston-Flatt, S. K. \& Marks, V. (1983). Abnormalities of GIP in spontaneous syndromes of obesity and diabetes in mice. Diabetes 32, 433-435.

Gerich, J. E., Charles, M. A. \& Grodsky, G. M. (1976). Regulation of pancreatic insulin and glucagon secretion. Annual Review of Physiology 38, 353-388.

Hampton, S. M., Kwasowski, P., Tan, K., Morgan, L. M. \& Marks, V. (1983). Effect of pretreatment with a high- 
fat diet on the gastric inhibitory polypeptide and insulin responses to oral triolein and glucose in rats. Diabetologia 24, 278-281.

Jones, I. R., Owens, D. R., Luzio, S. D. \& Hayes, T. M. (1989). Obesity is associated with increased post-prandial GIP levels which are not reduced by dietary restriction and weight loss. Diabète et Métabolisme 15, 11-22.

Lawes Agricultural Trust (1990). Genstat V. Rothamsted: Rothamsted Experimental Station.

Morgan, L. M., Flatt, P. R. \& Marks, V. (1988a). Nutrient regulation of the entero-insular axis and insulin secretion. Nutrition Research Reviews 1, 79-97.

Morgan, L. M., Hampton, S. M., Tredger, J. A., Cramb, R. \& Marks, V. (1988 b). Modifications of gastric inhibitory polypeptide (GIP) secretion in man by a high-fat diet. British Journal of Nutrition 59, 373-380.

Morgan, L. M., Morris, B. A. \& Marks, V. (1978). Radioimmunoassay of gastric inhibitory polypeptide. Annals of Clinical Biochemistry 15, 172-177.

Morgan, L. M., Tredger, J. A., Hampton, S. M., French, A. P., Peake, J. C. F. \& Marks, V. (1988c). The effect of dietary modification and hyperglycaemia on gastric emptying and gastric inhibitory polypeptide (GIP) secretion. British Journal of Nutrition 60, 29-37.

Morgan, L. M., Tredger, J. A., Hampton, S. M., Kwasowski, P., Wright, J., Dunn, M. \& Marks, V. (1983). Effect of diet upon response to oral fat and glucose in man: modification in control of the enteroinsular axis. Scandinavian Journal of Gastroenterology 18, suppl. 87, 99-101.

O'Dorisio, T. M., Cataland, S., Stevenson, M. \& Mazzaferri, E. L. (1976). Gastric inhibitory polypeptide (GIP). Intestinal distribution and stimulation by amino acids and medium-chain triglycerides. American Journal of Digestive Diseases 21, 761-765.

O’Dorisio, T. M., Sirinek, K. R., Mazzaferri, E. L. \& Cataland, S. (1977). Renal effects on serum gastric inhibitory polypeptide (GIP). Metabolism 26, 651-656.

Olefsky, J. M. \& Saekow, M. (1978). The effects of dietary carbohydrate content on insulin binding and glucose metabolism by isolated rat adipocytes. Endocrinology 103, 2252-2263.

Penman, E., Wass, J. A. H., Medback, S., Morgan, L. M., Lewis, J., Besser, G. M. \& Rees, L. H. (1981), Response of circulating somatostatin to nutritional stimuli in normal subjects. Gastroenterology 81, 692-699.

Polak, J. M., Bloom, S. R., Kuzio, M., Brown, J. C. \& Pearse, A. G. E. (1973). Cellular localisation of gastric inhibitory polypeptide in the duodenum and jejunum. Gut 14, 284-288.

Ponter, A. A., Salter, D. N., Morgan, L. M.\& Flatt, P. R. (1990). The effect of high-fat diets on gastric inhibitory polypeptide (GIP) and insulin in growing pigs. Animal Production 50, 571A.

Ross, G. J. S. (1980). Maximum likelihood programme (MLP). Rothamsted: Rothamsted Experimental Station.

Service, F. J., Rizza, R. A., Westland, R. E., Hall, L. D., Gerich, J. E. \& Go, V. L. W. (1984). Gastric inhibitory polypeptide in obesity and diabetes mellitus. Journal of Clinical Endocrinology and Metabolism 58, I133-1140.

Sun, J. V., Teppermam, H. M. \& Tepperman, J. (1977). A comparison of insulin binding by liver plasma membrane of rats fed a high glucose diet or a high fat diet. Journal of Lipid Research 18, 533-539.

Sykes, S., Morgan, L. M., English, J. \& Marks, V. (1980). Evidence for preferential stimulation of GIP secretion in the rat by actively transported carbohydrates and their analogues. Journal of Endocrinology 85, $201-207$.

Tan, K. S., Kwasowski, P. \& Marks, V. (1987). Effects of high-fat cafeteria diet on plasma insulin (IRI) and gastric inhibitory polypeptide (IR-GIP) response to a glucose load in the rat. Clinical Science 73, Suppl. 17, 57P.

Thomas, F. B., Sinar, D., Mazzaferri, E. L., Cataland, S., Mekhjian, H. S., Caldwell, J. H. \& Fromkes, J. J. (1978). Selective release of gastric inhibitory polypeptide by intraduodenal amino acid perfusion in man. Gastroenterology 74, 1261-1265.

Williams. R. H., May, J. M. \& Biesbroeck, J. B. (1981). Determinants of gastric inhibitory polypeptide and insulin secretion. Metabolism 30, 36-40. 